\title{
Special Issue Editors' Notes
}

Dr. Shams Forruque Ahmed, Dr. Ahmedul Kabir, Dr. AKM Moniruzzaman Mollah

\section{Preface}

This special issue consists of some selective papers submitted to the $5^{\text {th }}$ International Conference on Natural Science and Technology (ICNST'18). The papers were accepted by our peer review process. ICNST is organized by Science and Math Program of Asian University for Women (AUW) each year since 2014. The main aim of the conference is to bring forward the latest research advances in natural sciences and technology by the scientific and research communities, and provide a forum for the exchange of latest technical information, the dissemination of the high-quality research results on the issues, the presentation of the new developments in these areas, and the debate and shaping of future directions. The conference has maintained its uniqueness and yet evolved gradually to add extra dimension like the session on "Women in Science", increased overall number of sessions and has gone international for the first time this year. It is a multi-disciplinary conference on the topics of Biosciences and Bioinformatics, Environmental Sciences, Information and communication technologies, and Public Health.

Papers on related topics were solicited from all relevant disciplinary areas, ranging from current problems, projections, new concepts, modeling, experiments and measurements, to simulations. The ICNST'18 received extraordinary international attention over the world. It included plenary sessions, keynote lectures, and several specialized sessions on different topics including "women in science". The Women in Science session has been an integral part of the ICNST conference since 2014. The purpose of arranging this session is to create a platform for women researchers and scientists from STEM to share their journey and viewpoints on the contributions made by women in this field.

As we are all aware, the efforts required in organizing and holding this kind of Conference are extensive. We would like to take this opportunity to convey our heartfelt appreciation to some key individuals, all the members of the Organizing Committee, especially the students, who are the driving force behind this conference. We would also like to thank all the sponsors, attendees, presenters, reviewers, chairs of session and keynote \& invited speakers from Bangladesh and abroad for their contributions in making this conference a success. 